\title{
Inhaler treatment options in COPD
}

\author{
S.P. Newman
}

ABSTRACT: A variety of inhaler devices are available for delivering treatments to patients with chronic obstructive pulmonary disease, and new inhalers are currently being developed. Each type of device has advantages and disadvantages, and the methods of preparation and use vary between them. The differences in instructions for use can easily confuse patients and health providers alike, resulting in incorrect use of many inhalers. "Crucial" errors in inhaler technique, whereby no drug is deposited in the lungs, must be avoided. Any type of inhaler can be misused so that little or no drug is deposited in the lungs.

It is now increasingly widely recognised that a successful treatment outcome in chronic obstructive pulmonary disease depends as much on the inhaler device as it does on the drug. Inhaler choice in chronic obstructive pulmonary disease should take into account whether the patient is likely to use it correctly, as well as patient preference and the likelihood of adherence to treatment.

KEYWORDS: Chronic obstructive pulmonary disease, dry powder inhaler, pressurised metereddose inhaler, soft mist inhaler, spacer device

$\mathbf{T}$ he inhaled route is preferred for the delivery of bronchodilators and corticosteroids used in the maintenance therapy of asthma and chronic obstructive pulmonary disease (COPD). Small doses of drugs are delivered direct to their site of action, leading to a rapid onset of action and a low incidence of sideeffects. While guidance about appropriate selection of drugs for inhalation therapy is easily obtained [1-3], it is more difficult to source advice about the choice of inhaler device, despite the availability of several different types. The American College of Chest Physicians (ACCP) recently published evidence-based guidelines that listed eight points for consideration when selecting an inhaler, including taking account of any specific device preference the patient or clinician might have and whether a given patient can use the device properly [4]. Hence, an understanding of inhaler technology and issues of correct versus incorrect use are key factors affecting inhaler choice.

In this article, the main types of inhaler available for COPD therapy will be reviewed briefly, together with current understanding about correct and incorrect techniques for each device (table 1), and the advantages and disadvantages of the different types (table 2). Although nebulisers are frequently used to deliver COPD treatment, particularly to less mobile patients, most current designs are bulky and inconvenient, and treatment times are long. Therefore, they are better categorised as fall-back devices for most
COPD patients. As they are not true competitors to pressurised metered-dose inhalers (pMDIs) and dry powder inhalers (DPIs) for outpatient use, they have not been considered in this article.

It is assumed that inhaled drugs must be deposited within the lungs if they are to exert a beneficial effect [5]. Therefore, it is important to distinguish between "crucial" (or "essential") errors, which are likely to result in no drug reaching the lungs, and "non-crucial" errors, which are likely to result in a reduced amount of drug reaching the lungs compared with that attained using the correct technique [6]. Not all crucial errors are equally common in practice; table 3 shows the crucial errors made when using the device types covered in this article. Although a patient may know how to use a device correctly, this does not necessarily predict good compliance, as patients may contrive to use their inhalers incorrectly [7]. It may therefore be useful to distinguish between three types of compliance: "device competency", those who are able to use the device correctly but do not always do so in practice; "technique compliance", those who actually do use it correctly; and "regimen compliance", those who take the treatment as agreed with the prescriber.

\section{PRESSURISED METERED-DOSE INHALERS}

The pMDI was first introduced in 1956 to provide a delivery system for inhaled bronchodilators with a multi-dose capability and reproducible
CORRESPONDENCE

S.P. Newman

Scientific Consultant

Nottingham

UK

E-mail: steve.newman@physics.org 


\section{TABLE 1 Correct techniques for different types of inhaler and the errors patients are known to make}

Device Correct technique Errors in technique

"Press and breathe" pMDI

Breath-actuated pMDI

"Press and breathe" pMDI plus spacer

DPIs

Respimat $_{\mathbb{R}}$ Soft Mist $^{\mathrm{TM}}$ Inhaler $^{\#}$
Remove mouthpiece cap

Shake inhaler (suspensions only)

Hold inhaler upright

Breathe out

Place mouthpiece between lips

Fire while breathing in deeply and slowly

Continue to inhale after firing

Hold breath (10 s)

Remove mouthpiece cap

Shake inhaler (suspensions only)

Hold inhaler upright

Prepare device (e.g. lift lever)

Breathe out

Place mouthpiece between lips

Breathe in deeply and slowly

Continue to inhale after firing

Hold breath (10 s)

Remove mouthpiece cap

Shake inhaler (suspensions only)

Hold inhaler upright

Insert pMDI into spacer

Breathe out

Fire while breathing in deeply and slowly

Continue to inhale after firing

Hold breath (10 s)

Remove cover (device specific)

Load dose (device specific)

Pierce capsule (single-dose devices)

Breathe out

Place mouthpiece between lips

Inhale deeply and quickly

Hold breath (10 s)

Store in cool dry place

Hold upright and turn base

Open mouthpiece cap

Breathe out

Put mouthpiece between lips

Press dose release button while breathing

in deeply and slowly

Continue to inhale after firing

Hold breath (10 s)
Failure to remove mouthpiece cap*

Inhaler not shaken

Inhaler upside down*

No exhalation

Firing device before start of inhalation Firing device at or after end of inhalation* Inhaling through nose*

Stopping inhalation as device is fired*

Fast inhalation

$\mathrm{No}$ /short breath-hold

Failure to remove mouthpiece cap

Inhaler not shaken

Inhaler upside down*

Failure to prepare device correctly*

No exhalation

Poor seal around mouthpiece

Using "open mouth" inhalation technique*

Weak inhalation, failure to trigger device*

Inhaling through nose*

Stopping inhalation as device is fired*

Fast inhalation

No/short breath-hold

Inappropriate handling (static charge)

Failure to remove mouthpiece cap*

Inhaler not shaken

Inhaler upside down*

No exhalation

Long delay before inhalation

Multiple actuation

Weak inhalation, failure to open valve*

Inhaling through nose*

Stopping inhalation as device is fired*

Fast inhalation

$\mathrm{No}$ /short breath-hold

Failure to remove cover*

Incorrect dose loading ${ }^{\star}$

Failure to pierce capsule*

Breathing out into device*

Inhalation vents blocked

Poor seal round mouthpiece

Using "open-mouth" inhalation technique*

Not inhaling quickly enough*

Insufficient "acceleration"

Inhaling through nose*

No/short breath-hold

Inappropriate storage

Failure to prime device/load dose*

Failure to open mouthpiece cap*

No exhalation

Mouthpiece vents blocked

Firing device before start of inhalation

Firing device at or after end of inhalation* Inhaling through nose*

Stopping inhalation as device is fired*

Fast inhalation

No/short breath-hold

pMDI: pressurised metered-dose inhaler; DPI: dry powder inhaler. *: crucial error, likely to result in zero lung deposition of drug; ${ }^{*}$ : manufactured by Boehringer Ingelheim

$\mathrm{GmbH} \&$ Co. KG, Ingelheim, Germany; ${ }^{\circledR}$ : error that may be crucial. 
TABLE 2 Advantages and disadvantages of different inhaler devices

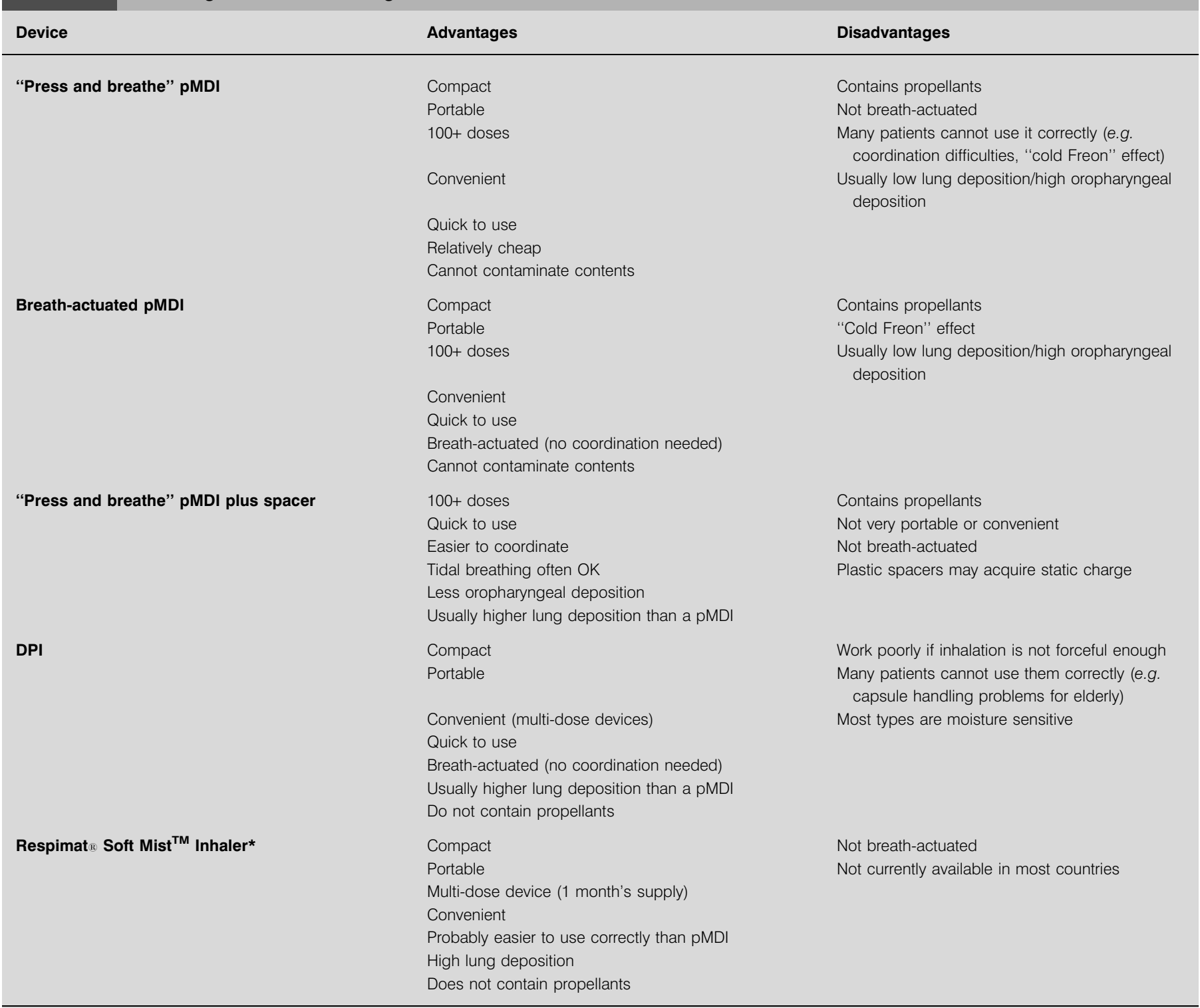

pMDI: pressurised metered-dose inhaler; DPI: dry powder inhaler. *: manufactured by Boehringer Ingelheim GmbH \& Co. KG, Ingelheim, Germany.

dosing characteristics [8].pMDIs contain propellants, which are currently being changed from chlorofluorocarbons (CFCs) to hydrofluoroalkanes (HFAs) because the former damage the ozone layer in the stratosphere [9]. The pMDI produces a rapid-moving plume of aerosol, the duration of which is typically $0.1-0.4 \mathrm{~s}$ [10]. The velocity of the aerosol plume may be $8 \mathrm{~m} \cdot \mathrm{s}^{-1}$ at a distance of $10 \mathrm{~cm}$ from the actuator, and is even higher at distances closer to the nozzle [10]. The plume often feels cold on the back of the throat as the propellants evaporate. Most pMDIs only deposit $10-20 \%$ of the dose in the lungs, even with good inhaler technique, and most of the dose is deposited in the oropharynx. Higher lung deposition and lower oropharyngeal deposition may be achieved with some recent formulations, where the drug is formulated as a solution in HFA propellant, rather than as a suspension of micronised particles [11].
Correct pMDI technique involves firing the pMDI, while breathing in deeply and slowly, and then following inhalation with a breath-holding pause to allow particles to sediment on the airway surfaces [12, 13]. Most instructions recommend placing the mouthpiece between closed lips, but it's also possible to hold the inhaler between open lips or even a few centimetres from the open mouth [14]. Misuse of pMDIs is common among patients $[15,16]$ and poor understanding of how to use a pMDI also appears to be widespread amongst health professionals $[17,18]$. Most importantly, the pMDI must not be fired after the patient has completed inhalation, as there will then be no airstream to carry the aerosol into the lungs. Some aerosol will probably still reach the lungs if the pMDI is fired shortly before inhalation begins. Failure to correctly time firing with inhalation is sometimes termed "poor coordination" [19]. The second major problem with pMDI 
TABLE 3 Crucial errors in inhaler use

Error

Devices affected

$\begin{array}{llll}\text { pMDI } & \text { BA pMDI } & \text { PMDI + spacer } \quad \text { DPI } \quad \text { Respimat } \text { Soft }\end{array}$

Mist $^{\mathrm{TM}}$ Inhaler $^{\mathrm{5}}$

Failure to remove mouthpiece cap or device cover Incorrect preparation/priming of device or loading of dose* Failure to pierce capsule Inhaler upside down Breathing out into device* Firing device at or after end of inhalation* Open-mouth inhalation technique Weak or very slow inhalation* Inhaling through nose Stopping inhalation as device is fired*

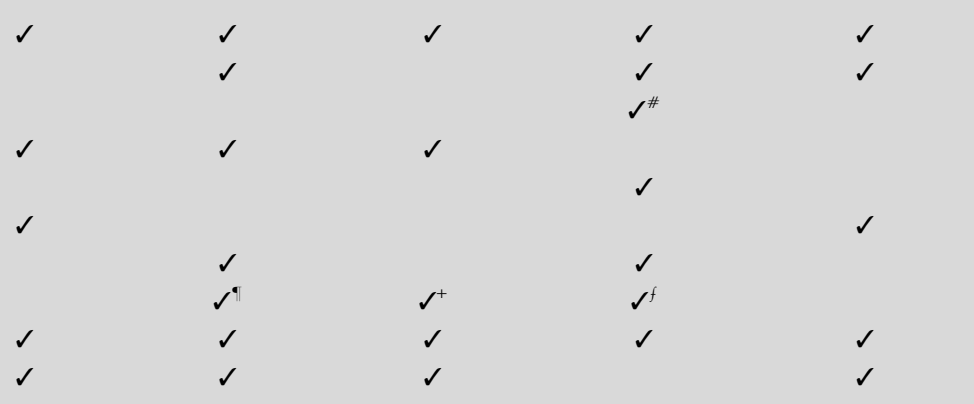

pMDI: pressurised metered-dose inhaler; BA pMDI: breath-actuated pMDI; DPI: dry powder inhaler. *: common errors; ${ }^{*}$ : single-dose devices; ${ }^{\bullet}$ : failure to trigger device : failure to open spacer valve; ${ }^{f}$ : too slow to aerosolise the dose; ${ }^{\S}$ : manufactured by Boehringer Ingelheim GmbH \& Co. KG, Ingelheim, Germany.

use is the so-called "cold Freon" effect, where the cold blast of propellants causes patients either to stop inhaling or to inhale via the nose [20]; this is probably less marked with HFA formulations. Patients who make errors in inhalation technique derive less clinical benefit than those with good technique [21], and this is particularly marked in those with poor coordination [22].

Despite the difficulties of using them correctly, pMDIs remain popular for delivering inhaled therapies in asthma and COPD because of their practical advantages: pMDIs contain at least 100 doses and are compact, portable, convenient and relatively inexpensive.

\section{BREATH-ACTUATED PRESSURISED METERED-DOSE INHALERS}

Since poor coordination between firing and inhaling is usually considered to be the most significant problem patients have with pMDIs [19], the development of breath-actuated (BA) pMDIs is logical. Two such devices (Autohaler ${ }^{\mathrm{TM}}$ (3M Pharmaceuticals, St Paul, MN, USA) and Easibreathe ${ }^{\mathrm{TM}}$ (Ivax, Miami, FL, USA)) are currently being marketed and several others are in development [11]. With BA pMDIs, the patient's inhalation through the device triggers a mechanism that fires the pMDI, so that firing and inhaling are automatically coordinated. These devices can achieve good lung deposition and clinical efficacy in patients unable to use a standard "press and breathe" pMDI correctly because of coordination difficulties [23].

BA pMDIs do not solve cold Freon problems and would be unsuitable for a patient who has this kind of difficulty using pMDIs. However, errors when using BA pMDIs are less frequent than when using a standard pMDI [24, 25]. It is essential that the BA pMDI is correctly prepared (e.g. by raising the priming lever, removing the mouthpiece cover etc.); the inhalation must also be strong enough to trigger the firing mechanism (the triggering flow is $20-30 \mathrm{~L} \cdot \mathrm{min}^{-1}$ for currently available devices).

\section{PRESSURISED METERED-DOSE INHALERS PLUS SPACER DEVICES}

Spacer devices are attachments to the inhaler mouthpiece with a volume ranging from $20-750 \mathrm{~mL}$. Their design and performance has been discussed in detail elsewhere [26, 27]. Many have a one-way valve in the mouthpiece, which prevents the patient blowing the dose away after firing. However, inhalation must be strong enough to trigger the one-way valve, otherwise no dose will be delivered. Spacers overcome coordination problems because inhalation can take place either as the device is fired into the spacer or after a short pause, with the latter method being recommended for some models. Cold Freon problems are unlikely with spacer devices because the point of aerosol generation is more remote from the mouth compared with a pMDI.

Tidal breathing from the spacer after firing a dose may be acceptable for some models [28] but multiple actuations, long delays between firing and inhaling, and the accumulation of static charge on some plastic spacer devices are likely to reduce the dose available for inhalation [29, 30]. Ideally, each pMDI dose should be inhaled separately from the spacer. Specific handling and washing techniques for different spacers are generally recommended to minimise static charge build-up.

While spacers are good drug-delivery devices, they suffer from the obvious disadvantages of making the entire delivery system less portable, compact and convenient than a standard pMDI.

\section{DRY POWDER INHALERS}

DPIs were first introduced in 1970, and the earliest models were single-dose devices containing the powder formulation in a gelatine capsule, which the patient loaded into the device prior to use. Since the late 1980s, multi-dose devices have been available, giving the same degree of convenience as a pMDI. The first of these was the Turbuhaler ${ }^{\mathrm{TM}}$ (AstraZeneca, Lund, Sweden). By early 2005, at least 17 DPIs were marketed in different countries, consisting of both single-dose and 
multi-dose models [31]. Most multi-dose DPIs hold the powder in a reservoir, from which individual doses are metered, but the Diskus ${ }^{\circledR}$ (GlaxoSmithKline, North Carolina, NC, USA) holds the doses in individually sealed foil blisters. DPIs may be more expensive than pMDIs but this will vary according to pricing policies in different countries.

All currently marketed DPIs are breath-actuated and no propellants are needed to generate the aerosol [32]. The patient's inhalation through the device is used to disperse the powder formulation and to deliver it into the lungs. However, patients can make crucial errors with a DPI; for instance, by failing to load a dose correctly or by exhaling into the DPI so that the dose is blown away [33]. Unless clearly instructed, some patients might not know that they must firmly seal their lips around the mouthpiece, causing them to attempt an "open mouth" inhalation technique that will not deliver any dose. The Turbuhaler ${ }^{\mathrm{TM}}$ DPI, and possibly other DPIs in which doses are metered from a bulk powder reservoir, must be kept upright (held vertically) when loading a dose before inhalation, so that the dosing chamber will fill under gravity [34]. Compared with a standard pMDI, fewer patients demonstrate errors in inhaler technique with a DPI $[24,25]$. Many DPIs must be stored in a dry environment to prevent the drug formulation being degraded by moisture.

DPIs tend to work better with rapid and forceful inhalation, since this disperses the powder formulation into small "respirable" particles as efficiently as possible [31]. Delivery to the lungs may be reduced with slow inhalation and for each DPI it is necessary for patients to attain a minimum inhaled flow rate in order to ensure that some drug is delivered to the lungs [6]. It is also desirable that the rate of increase of inhaled flow at the start of inhalation should be as high as possible [35]. This is sometimes called high flow "acceleration" or high "early flow".

In theory, the need to inhale forcefully could be a problem for some patients, especially those with more severe obstructive airways disease. However, a recent review [36] concluded that most patients can generate sufficient flows through DPIs to benefit from them, including $98 \%$ of asthmatic patients undergoing severe exacerbations needing hospitalisation. Most studies in which patients' inhaled flow rates through DPIs were assessed, have involved asthmatic patients. However, in one study [37], COPD patients with a mean forced expiratory volume in one second (FEV1) of $0.7 \mathrm{~L}$ could generate peak inhaled flow rates of $28-78 \mathrm{~L} \cdot \mathrm{min}^{-1}$ via the Turbuhaler ${ }^{\mathrm{TM}}$ DPI.

\section{SOFT MIST INHALERS}

The development of soft mist inhalers (SMIs) has opened up new opportunities for inhaled drug delivery. SMIs use liquid formulations similar to those in nebulisers, but are generally multi-dose devices that have the potential to compete with pMDIs and DPIs in the portable inhaler market.

While a number of SMIs are known to be in development [38, 39], the only device currently marketed is Respimat ${ }$ Soft Mist $^{\mathrm{TM}}$ Inhaler (Boehringer Ingelheim $\mathrm{GmbH} \&$ Co. KG, Ingelheim, Germany). This device contains sufficient doses of a bronchodilator formulation for 1 month's dosing, stored in a fluid reservoir [40]. Respimat ${ }_{\circledast}$ Soft Mist ${ }^{\mathrm{TM}}$ Inhaler is powered by the energy of a compressed spring inside the inhaler; no propellants are required. Individual doses are delivered via a precisely engineered nozzle system as a slow-moving aerosol cloud (hence the term "soft mist"). The velocity of the spray from Respimat ${ }_{\circledast}$ Soft Mist ${ }^{\mathrm{TM}}$ Inhaler is only about one-tenth of that from a CFC-based pMDI [10]. However, scintigraphical studies have shown that lung deposition is several times higher than that from a CFC-based pMDI [41], and clinical trials have confirmed that drugs delivered by the Respimat $\mathbb{R}$ Soft Mist ${ }^{\mathrm{TM}}$ Inhaler are effective in correspondingly smaller doses in COPD patients [42].

Respimat ${ }^{\circledR}$ Soft Mist ${ }^{\mathrm{TM}}$ Inhaler is a "press and breathe" device, and the correct inhalation technique closely resembles that used with a pMDI. While coordination between firing and inhaling is required, the low spray velocity and long duration of the aerosol cloud (typically 1-1.5 s) should enable patients to coordinate firing and inhaling more easily than with a pMDI [43]. Respimat ${ }$ Soft Mist ${ }^{\mathrm{TM}}$ Inhaler has been used relatively little in clinical practice to date, and could prove to have advantages or disadvantages additional to those listed in table 2.

\section{CONCLUSION}

A variety of inhaler devices are now available to deliver inhaled drugs to patients with COPD. The inhaled drug delivery field is a dynamic one, with many inhalers available already and new ones being introduced on a regular basis. The plethora of inhaler devices available, requiring different inhalation techniques for optimal drug delivery, may confuse patients and healthcare providers alike, a situation described as "device dementia" [44]. That said, a number of actions or steps are common to all types of devices reviewed in this article (table 4). For healthcare professionals and patients, these are arguably the most important elements of inhaler technique for the purposes of teaching and learning how to use each device, as most patients are likely to try more than one type of inhaler device during their lifetime and mastering a new device will thus be made easier. The final step in the sequence for all devices is the breath-hold. Studies of pMDI use show that lung deposition is greater after holding the breath for $10 \mathrm{~s}$ than for $4 \mathrm{~s}$ [45], because the extra time allowed for sedimentation in the small airways of the lung increases the amount of inhaled drug that is deposited. Given that the particle size distribution of aerosols delivered by the other

\section{TABLE 4 Common requirements for all devices reviewed}

Remove mouthpiece cap if present

Orientate inhaler correctly (e.g. upright for pMDI)

Breathe out

Place mouthpiece between lips

Breathe in deeply and slowly*,\#

Hold breath for $10 \mathrm{~s}$

pMDI: pressurised metered-dose inhaler. *: breathe in deeply and quickly for dry powder inhalers; \#: for "press and breathe" pMDI, actuate inhaler while breathing in. 


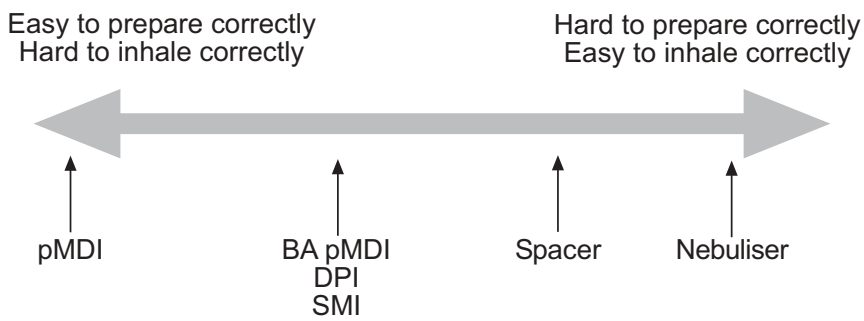

FIGURE 1. Diagrammatic scale contrasting ease of use with ease of preparation. pMDI: pressurised metered-dose inhaler; BA pMDI: breath-actuated pMDI; DPI: dry powder inhaler; SMI: soft mist inhaler.

devices in this article is quite similar to that from pMDIs, breath-holding is likely to have equal value in patients who use them.

There is no perfect inhaler, and each has advantages and disadvantages, but there is increasing recognition that a successful clinical outcome is determined as much by choice of an appropriate inhaler device as by the drugs that go in them [46]. Drug delivery from all inhaler devices depends on how the patient prepares the device and then inhales from it. The relative difficulties in completing these two steps correctly can be shown on a scale (fig. 1), with pMDI being the easiest to prepare (and hardest to inhale from correctly) and nebulisers at the opposite end. The best device for COPD patients is arguably one for which both these steps can be performed successfully without major challenges.

There is evidence that a patient is most likely to use correctly an inhaler that he or she prefers [25], and each patient's choice of device will be determined by individual perceptions of how its advantages and disadvantages balance out. This decision could be quite different to the judgement of a prescriber or a formulator, who may give more weight to technical points. Choice of an inhaler device should therefore take into account the likelihood that patients will be able to use a particular device correctly, cost-effectiveness, preference and likely compliance.

\section{SUMMARY}

- A variety of portable inhaler devices are now available for treating patients with chronic obstructive pulmonary disease and more new designs are in development; each type of device has advantages and disadvantages.

- The plethora of inhalers with differing instructions may confuse patients and healthcare providers alike.

- Any inhaler can be misused so that little or no drug is deposited in the lungs.

- "Crucial" errors in inhaler technique, resulting in no drug deposition in the lungs, must be avoided.

- There is increasing recognition that a successful treatment outcome in chronic obstructive pulmonary disease depends as much on the inhaler device as on the drug.

- Inhaler choice in chronic obstructive pulmonary disease should take into account: the likelihood of the patient using the inhaler correctly; patient preference; and likely compliance.

\section{REFERENCES}

1 Fabbri LM, Hurd SS. Global Strategy for the Diagnosis, Management and Prevention of COPD: 2003 update. Eur Respir J 2003; 22: 1-2.

2 Celli BR, MacNee W, and committee members. Standards for the diagnosis and treatment of patients with COPD: a summary of the ATS/ERS position paper. Eur Respir J 2004; 23: 932-946.

3 Global strategy for asthma management and prevention. NHLBI/WHO workshop report number 95-3659. Bethesda, National Institute of Health, 2002.

4 Dolovich MB, Ahrens RC, Hess DR, et al. Device selection and outcomes of aerosol therapy: Evidence-based guidelines: American College of Chest Physicians/American College of Asthma, Allergy, and Immunology. Chest 2005; 127: 335-371.

5 Derom E, Thorsson L. Factors affecting the clinical outcome of aerosol therapy. In: Bisgaard $\mathrm{H}, \mathrm{O}^{\prime}$ Callaghan C, Smaldone GC, eds. Drug Delivery to the Lung. New York, Marcel Dekker, 2002; pp. 143-171.

6 van der Palen J, Klein JJ, Kerkhoff AH, van Herwaarden CL, Seydel ER. Evaluation of the long-term effectiveness of three instruction modes for inhaling medicines. Patient Educ Couns 1997; 32: S87-S95.

7 Brennan VK, Osman LM, Graham H, Critchlow A, Everard ML. True device compliance: the need to consider both competence and contrivance. Respir Med 2005; 99: 97-102.

8 Thiel CG. From Susie's question to CFC free: an inventor's perspective on forty years of MDI development and regulation. In: Dalby RN, Byron PR, Farr SJ, eds. Respiratory Drug Delivery V. Buffalo Grove, Interpharm Press, 1996; pp. 115-123.

9 McDonald KJ, Martin GP. Transition to CFC-free metered dose inhalers-into the new millennium. Int J Pharm 2000; 201: 89-107.

10 Hochrainer D, Hölz H. Comparison of the aerosol velocity and spray duration of Respimat ${ }^{\circledR}$ Soft Mist ${ }^{\mathrm{TM}}$ inhaler and pressurised metered dose inhalers. J Aerosol Med 2005; 18: 273-282.

11 O'Callaghan $\mathrm{C}$, Wright $\mathrm{P}$. The metered-dose inhaler. In: Bisgaard H, O'Callaghan C, Smaldone GC, eds. Drug Delivery to the Lung. New York, Marcel Dekker, 2002; pp. 337-370.

12 Newman SP, Pavia D, Clarke SW. How should a pressurized beta-adrenergic bronchodilator be inhaled? Eur J Respir Dis 1981; 62: 3-21.

13 Hindle M, Newton DA, Chrystyn H. Investigations of an optimal inhaler technique with the use of urinary salbutamol excretion as a measure of relative bioavailability to the lung. Thorax 1993; 48: 607-610.

14 Connolly CK. Method of using pressurized aerosols. BMJ 1975; 3: 21.

15 Epstein SW, Manning CP, Ashley MJ, Corey PN. Survey of the clinical use of pressurized aerosol inhalers. Can Med Assoc J 1979; 120: 813-816.

16 Shim C, Williams MH Jr. The adequacy of inhalation of aerosol from canister nebulizers. Am J Med 1980; 69: 891-894.

17 Kelling JS, Strohl KP, Smith RL, Altose MD. Physician knowledge in the use of canister nebulizers. Chest 1983; 83: 612-614. 
18 Kesten S, Zive K, Chapman KR. Pharmacist knowledge and ability to use inhaled medication delivery systems. Chest 1993; 104: 1737-1742.

19 Crompton GK. Problems patients have using pressurized aerosol inhalers. Eur J Respir Dis Suppl 1982; 119: 101-104.

20 Pedersen S, Ostergaard PA. Nasal inhalation as a cause of inefficient pulmonal aerosol inhalation technique in children. Allergy 1983; 38: 191-194.

21 Lindgren S, Bake B, Larsson S. Clinical consequences of inadequate inhalation technique in asthma therapy. Eur J Respir Dis 1987; 70: 93-98.

22 Giraud V, Roche N. Misuse of corticosteroid metered-dose inhaler is associated with decreased asthma stability. Eur Respir J 2002; 19: 246-251.

23 Newman SP, Weisz AW, Talaee N, Clarke SW. Improvement of drug delivery with a breath actuated pressurised aerosol for patients with poor inhaler technique. Thorax 1991; 46: 712-716.

24 Molimard M, Raherison C, Lignot S, et al. Assessment of handling of inhaler devices in real life: an observational study in 3811 patients in primary care. J Aerosol Med 2003; 16: 249-254.

25 Lenney J, Innes JA, Crompton GK. Inappropriate inhaler use: assessment of use and patient preference of seven inhalation devices. Respir Med 2000; 94: 496-500.

26 Newman SP, Newhouse MT. Effect of add-on devices for aerosol drug delivery: deposition studies and clinical aspects. J Aerosol Med 1996; 9: 55-70.

27 Newman SP. Spacer devices for metered dose inhalers. Clin Pharmacokinet 2004; 43: 349-360.

28 Gleeson JG, Price JF. Nebuhaler technique. Br J Dis Chest 1988; 82: 172-174.

29 Barry PW, O'Callaghan C. The effect of delay, multiple actuations and spacer static charge on the in vitro delivery of budesonide from the Nebuhaler. Br J Clin Pharmacol 1995; 40: 76-78.

30 Wildhaber JH, Devadason SG, Eber E, et al. Effect of electrostatic charge, flow, delay and multiple actuations on the in vitro delivery of salbutamol from different small volume spacers for infants. Thorax 1996; 51: 985-988.

31 Newman SP. Dry powder inhalers for optimal drug delivery. Expert Opin Biol Ther 2004; 4: 23-33.

32 Smith IJ, Parry-Billings M. The inhalers of the future? A review of dry powder devices on the market today. Pulm Pharmacol Ther 2003; 16: 79-95.
33 Pedersen S, Frost L, Arnfred T. Errors in inhalation technique and efficiency in inhaler use in asthmatic children. Allergy 1986; 41: 118-124.

34 Hesselink AE, Penninx BW, Wijnhoven HA, Kriegsman DM, van Eijk JT. Determinants of an incorrect inhalation technique in patients with asthma or COPD. Scand J Prim Health Care 2001; 19: 255-260.

35 Everard ML, Devadason SG, Le Souef PN. Flow early in the inspiratory manoeuvre affects the aerosol particle size distribution from a Turbuhaler. Respir Med 1997; 91: 624-628.

36 Borgstrom L. On the use of dry powder inhalers in situations perceived as constrained. J Aerosol Med 2001; 14: 281-287.

37 Dewar MH, Jamieson A, McLean A, Crompton GK. Peak inspiratory flow through Turbuhaler in chronic obstructive airways disease. Respir Med 1999; 93: 342-344.

38 Hindle M. Soft mist inhalers: a review of current technology. Drug Delivery Companies Report. Autumn/ Winter 31-34. Oxford, Pharmaventures Ltd, 2004.

39 Byron PR. Drug delivery devices: issues in drug development. Proc Am Thorac Soc 2004; 1: 321-328.

40 Zierenberg B. Optimizing the in vitro performance of Respimat. J Aerosol Med 1999; 12: Suppl. 1, S19-S24.

41 Newman SP. Use of gamma scintigraphy to evaluate the performance of new inhalers. J Aerosol Med 1999; 12: Suppl. 1, S25-S31.

42 Kassner F, Hodder R, Bateman ED. A review of ipratropium bromide/fenoterol hydrobromide (Berodual) delivered via Respimat Soft Mist Inhaler in patients with asthma and chronic obstructive pulmonary disease. Drugs 2004; 64: 1671-1682.

43 Dalby R, Spallek M, Voshaar T. A review of the development of Respimat Soft Mist Inhaler. Int J Pharm 2004; 283: 1-9.

44 Fink JB, Rubin BK. Problems with inhaler use: a call for improved clinician and patient education. Respir Care 2005; 50: 1360-1375.

45 Newman SP, Pavia D, Garland N, Clarke SW. Effects of various inhalation modes on the deposition of radioactive pressurized aerosols. Eur J Respir Dis Suppl 1982; 119: 57-65.

46 Barnes PJ, Pedersen S, Busse WW. Efficacy and safety of inhaled corticosteroids. New developments. Am J Respir Crit Care Med 1998; 157: S1-S53. 